\title{
Human Herpesvirus 6 Positive
}

National Cancer Institute

\section{Source}

National Cancer Institute. Human Herpesvirus 6 Positive. NCI Thesaurus. Code C141401.

An indication that human herpesvirus 6 has been detected in a sample. 